\title{
Implementation of Business Process Reengineering Based on Workflow Management
}

\author{
Wen Yang ${ }^{1}$ and Hongjiang Chen ${ }^{2}$ \\ ${ }^{1}$ School of Mechanical and Electrical Engineer, \\ Jiangxi Science \& Technology Normal University, \\ Nanchang, Jiangxi 330013, P.R. China \\ ${ }^{2}$ School of Mechanical and Electrical Engineer, \\ Jiangxi Science \& Technology Normal University, \\ Nanchang, Jiangxi 330013, P.R. China \\ \{Wen Yang, Hongjiang Chen, hongjiangc\}@163.com
}

\begin{abstract}
To achieve better performance of BPR, workflow management is integrated with BPR based on the core idea and steps of BPR. Main problems of hotel business process are studied, at the same the characteristics and advantages of WFM are introduced, which show that WFM is sound. Then BPR case of a five-star hotel in Guangzhou which adopts the WFM workflow is proposed. The rent and service charge processes are analyzed; the collaborative workflow and its new process after reengineering are also given, which achieve better results.
\end{abstract}

Keywords: Business Process (BP), Business Process Reengineering (BPR), Workflow Management (WFM), Workflow Management System (WFMS).

\section{Introduction}

Customer, competition, change and the theme of external environment make the service of hotel more flexible and comprehensive, which change management from occupation-center to process-centric. Business Process Reengineering (BPR), firstly introduced by Hammer, has become a powerful way to continuously optimize business process (BP) and improve hotel's core competitiveness [1]. Now many organizations have implemented BPR for improving their performances [2]. Yet it is lack of effective implementation tools, which makes it very difficult to achieve desired results. Workflow technology can strengthen the control of BP and enhance BP's flexibility and applicability through modeling, analysis and improvement, which can avoid failure effectively in the application of new processes caused by human and resource factors [3]. Workflow technology is the core technology for integration of the implementation of BPR, management and technology. 


\section{BPR of Hotel}

\subsection{Main Problems of Hotel Business Process}

To meet the competition, modern hotel management is required to not only good and efficient service, but also is expected to achieve maximum profits and more flexibility. Hotel operating activities is to including forecast, decision-making, control, responsibility assessment and evaluation of the entire management process and so on. Though the hotel management developed quiet well in the past years, there are still a lot of problems to overcome.

According to the statistics, about $70 \%$ of activity in an organization is related with the process activity [4], so BP plays an important role in organization efficiency. However, BP is divided into a variety of simple tasks in the way of dividing traditional labor. Each unit is subject to its senior official, but not responsible for customer directly, which don't work to solve problems and improve their work. For example, changing requests of the scheduled banquet is quiet time-consuming and involves several departments. Therefore, it is urgent to change the organizational structure from the traditional way to the market-oriented, ie. task-oriented to processoriented.

Most hotels have introduced corresponding information systems such as marketing system, financial system, and so on [5]. But these systems are often only authorized to the respective department to specific issues and work well in the internal management. Yet they are not market-oriented and customer-oriented. Secondly, each BP change may causes significant changes in program structure, because these BP have been coded with software programs. Furthermore, the resource utilization's rate is low. In addition, they are very difficult to modify the process reengineering, because these systems are developed by different software corporations.

The hotel's BPR should be customer-oriented, integrating with key BP, reducing non-value-added chain and complex chain of operational steps.

\subsection{BPR Based on Workflow Management}

BPR, re-thinking and re-engineering business process [6] delivers a lot of changes to organizational structure and business processes, which risks a lot at the same. Now the BPR works not well, which were reported $70 \%$ projects fail to achieve the desired objectives and even flat failure [7]. To build up its practical implementation, it's should be further explored and improved.

Workflow management (WFM) is a fast evolving technology, which is used in a variety of industrial processes. Workflow is concerned with the automation of procedure, whose documents, information or tasks are passed between participants according to a defined set of rules to achieve an overall business goal. A Workflow Management System (WFMS) defines, creates and manages the execution of workflows based on software, which is able to interpret the process definition, interact 
with workflow participants and invoke the use of IT tools and applications where required [WfMC99a] [8]. The evolution of WFM concentrates on the automation of business processes where interactions of human and machine-based activities play a major role. Within workflows, information or tasks are passed among participants in a way that is governed by rules or procedures.

Workflow is often associated with BPR, which is concerned with the assessment, analysis, modeling, definition and subsequent operational implementation of the core BP of an organization (or other business entity) [9]. Although not all BPR activities result in workflow implementations, workflow technology is often an appropriate solution as it provides separation of the business procedure logic and its IT operational support, enabling subsequent changes to be incorporated into the procedural rules defining the BP. Figure 1 shows the basic characteristics of WFMS and relationships between these main functions (WfMC95).

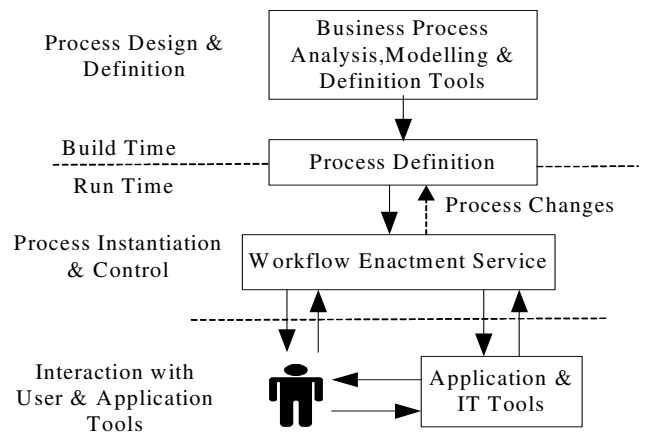

Fig. 1. Workflow system characteristics

At the highest level, all WFM systems may be characterized as providing support in three functional areas. The Build-time functions are concerned with defining, and possibly modeling the workflow process and its constituent activities. The Run-time control functions are concerned with managing the workflow processes in an operational environment and sequencing the various activities to be handled as part of each process. The Run-time interactions are concerned with human users and IT application tools for processing the various activities [10].

\section{An Implementation Case}

\subsection{Analysis for Information Exchange of a Hotel Business}

In this paper, a case for a five-star hotel in Guangzhou sets out the application of BPR based on WFMS in the hotel industry. Information data exchange and sharing process of the hotel based on workflow management system is shown in figure 2 . 


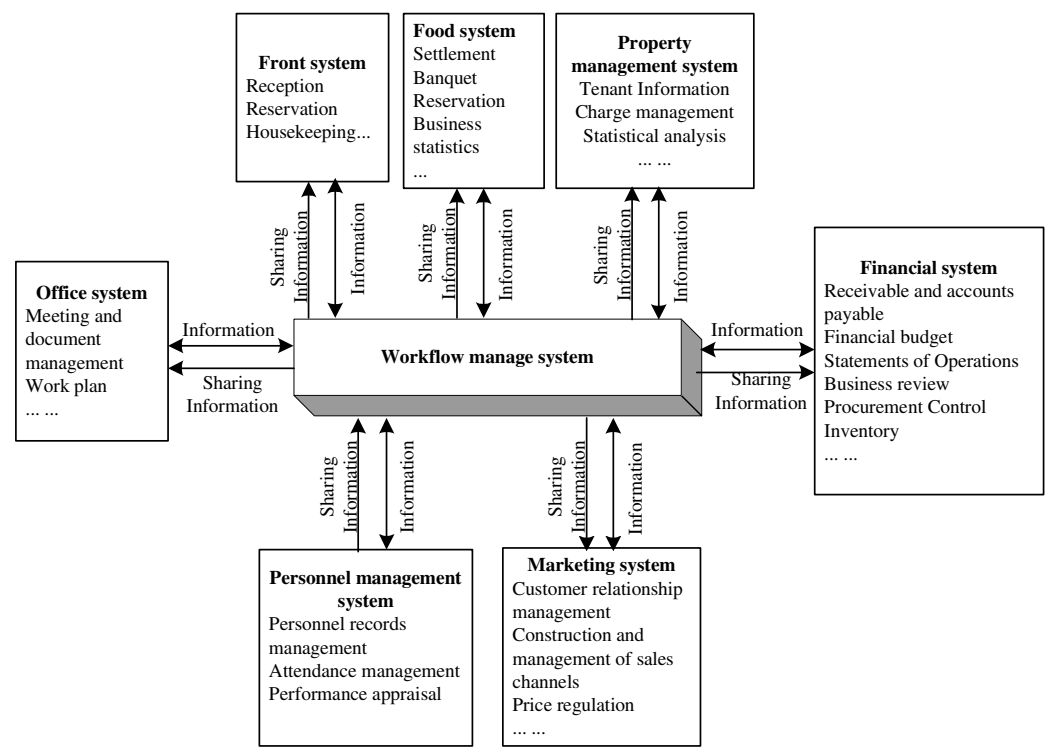

Fig. 2. Information data exchange and sharing process of the hotel based on workflow management system

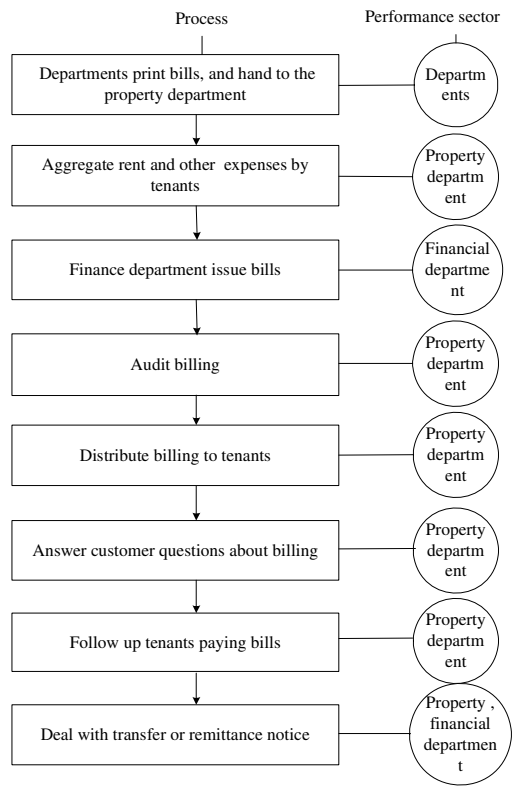

Fig. 3. Old process of rent and service charge 


\subsection{Analysis of Rent and Service Charge Process}

BPR of rent and service charge process in the hotel as an example is to elaborate for the space limitation. Processes for rent and service charge involve nearly all departments and consumption points. If they can be effectively improved, hotel can significantly improve efficiency, enhance customer satisfaction and its image, and provide data to support marketing.

Figure 3, an old process of rent and service charge, indicates some inadequacy which are more review and transmission of documents between various departments, more heavy workload and error-prone, isolation between property management systems and financial management systems, repeating input of information, low work efficiency, and delayed analysis of relevant business data, and so on.

\subsection{BPR of Rent and Service Charge Process}

To connect data interface of property management system, consumption point and financial management system, the workflow system is developed based on WFM. Without changing the existing application software, the information can be automatically transmitted to the relevant application software according to the predefined rules. Consumption data can automatically transfer to property and financial management systems with the WFM, and can be analyzed and gathered in time.

The platform of collaborative workflow and its new process after reengineering are shown as Fig.4.

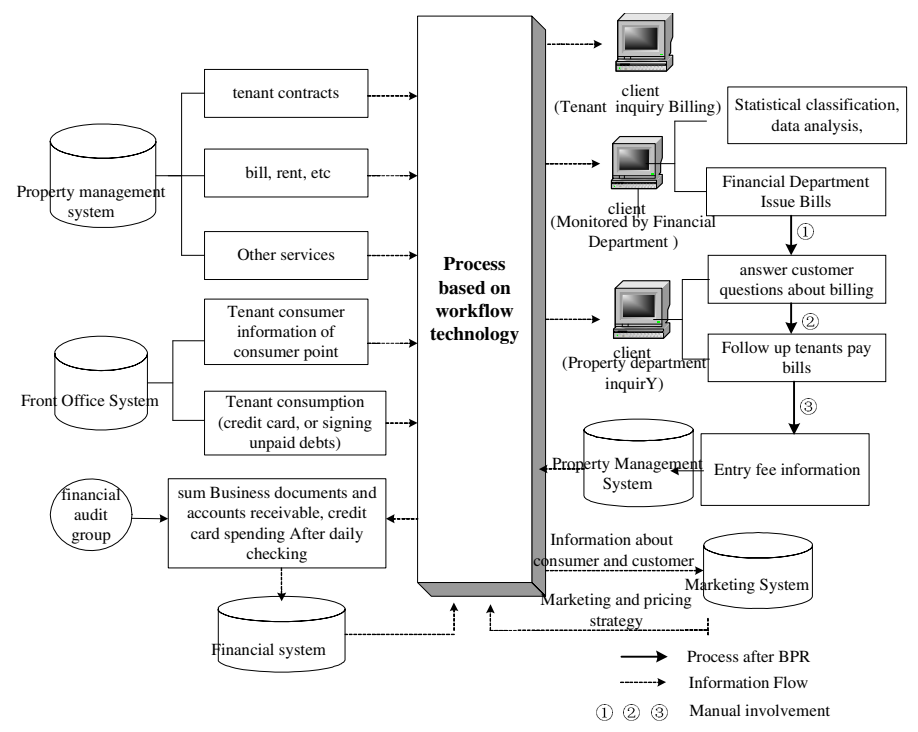

Fig. 4. Flow of mechanism and platform for collaborative workflow and its new process after reengineering 
The BPR based on workflow technology can optimize processes of the rents and service charge, coordinate the work of various departments, and transfer the information to the related departments. At the same time, all application software and their business processes, such as property management system and financial management system, are systematically integrated and implemented automatically, which greatly Shorten the execution time, eliminate redundancy non-value process. Financial department, property department and marketing department can jointly develop marketing programs by real-time tracking consumer information and consumer trends. Furthermore the BPR can avoid human factors and resource affecting the implementation of new processes, so that the overall process can achieve optimal.

\section{Conclusions}

To optimize the business processes, BPR based on WFMS is simulated in this paper. The Simulation results show that BPR is more effective and flexible.

Acknowledgments. The paper is one of the results of project, the Project of BPR and Information Network System in the Garden Hotel, supported by Guangzhou Garden Hotel.

\section{References}

[1] Hammer, M.: Harvard Business Review (July/August 1990)

[2] Worley, J.H., Castillo, G.R., Geneste, L., Grabot, B.: Computers in Industry, vol. 49 (2002)

[3] Workflow Management Coalition, Terminology and Glossary, Document Number WFMC-TC-1011, Issue 3.0 (1999)

[4] Lawrence, P. (ed.): Workflow Handbook. Wiley, New York (1997)

[5] Cheung, Y., Bal, J.: Process analysis techniques and tools for business improvements. Business Process Management Journal 4(4), 274-290 (1998)

[6] Eatock, J., Serrano, A., Giaglis, G.M., Paul, R.J.: A Case Study on Integrating Business and Network Simulation for Business Process Redesign. In: The Proceedings of the 4th United Kingdom Simulation Society Conference, Cambridge, pp. 114-118 (1999)

[7] Hansen, G.: Automating Business Process Reengineering, p. 40. Prentice-Hall (1994)

[8] Hammer, M., Champy, J.: Reengineering the Corporation: A Manifesto for Business Revolution. Harper Collins, London (1993)

[9] Hayes, J.G., Peyrovian, E., Sarin, S., Schmidt, M.T., Swenson, K.D., Weber, R.: Workflow Interoperability Standards for the Internet. IEEE Internet Computing 4(3), 37-45 (2000)

[10] Workflow Management Coalition, The Workflow Reference Model, Document Number TC00-1003 